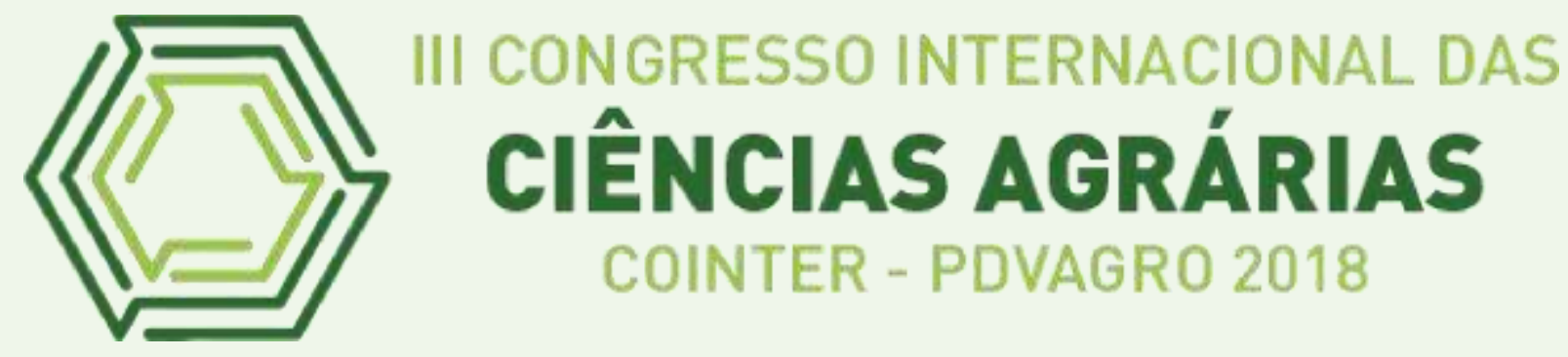

\title{
EDUCAÇÃO AMBIENTAL: ANÁLISE QUANTITATIVA DA ÁGUA CONDENSADA DE APARELHOS DE AR-CONDICIONADOS, PROPOSTA E SOLUÇÕES PRÁTICAS.
}

\section{ENVIRONMENTAL EDUCATION: QUANTITATIVE ANALYSIS OF CONDENSED WATER FROM AIR CONDITIONING APPLIANCES, PROPOSAL AND PRACTICAL SOLUTIONS}

\author{
Apresentação: Pôster \\ Jucigleice Pascoal Salgado ${ }^{\text {; }}$ João Paulo da Silva Sousa²; Gláucio Sousa Martins³ . \\ DOI: https://doi.org/10.31692/2526-7701.IIICOINTERPDVAGRO.2018.00438
}

\section{Introdução}

Os aparelhos de ar condicionado promovem a geração de água resultante da condensação, que na maioria das vezes é desperdiçada para o solo ou para o esgoto. Desta forma, o aproveitamento da água, depende da coleta eficiente de cada sistema de drenagem dos aparelhos, os quais podem ser direcionados para um sistema de coleta e armazenamento (RIGOTTI, 2014)

Com a crescente urbanização das cidades iniciou o processo de degradação ambiental, necessitando de uma discussão mais dinâmica sobre a sustentabilidade do meio ambiente. A educação ambiental abordando assuntos que envolvam a manutenção da qualidade da água, do ar e do solo se torna urgente a partir do instante em que a qualidade de vida está intrinsecamente ligada a manutenção desses recursos (JACOBI, 2003).

O problema da escassez de recursos hídricos leva a sociedade a buscar alternativas do uso sustentável da água como técnicas de aproveitamento de água da chuva e água como as geradas por aparelhos de ar condicionado (CARVALHO et. al, 2016).

Portanto, o objetivo deste trabalho foi o de quantificar a água oriunda do processo de climatização de ambientes, resultante da condensação da água contida na massa de ar quente,

\footnotetext{
${ }^{1}$ Engenharia Florestal, UFRA/Capitão Poço, juci.pier@hotmail.com

${ }^{2}$ Licenciatura em Ciências Agrárias, IFMA /Campus Codó, joaopauloneto1.00@gmail.com

${ }^{3}$ Licenciatura em Informática, UFMA/Campus Codó, glauciosmartins@gmail.com
} 
das salas de aulas dos blocos A, B e C do Instituto Federal de Educação, Ciência e Tecnologia do Maranhão - IFMA Campus Codó.

\section{Fundamentação Teórica}

A água é um dos recursos mais valiosos do planeta, contribuindo fortemente para a existência da vida, devido as suas propriedades distintas. Por essa razão a gestão responsável da água é fundamental para a perpetuação dos seres vivos. Porém, por maior que seja sua importância, as pessoas continuam a poluir os rios e suas nascentes, sendo assim obrigados a consumi-la. A qualidade e volume de água existente na natureza vêm diminuindo gradativamente, decorrente da expansão da agricultura, indústria e principalmente pela degradação do meio ambiente (REBOUCAS et. al, 2016).

A lei das águas 9433/97 foi um grande passo dado por entidades governamentais, especialmente os órgãos voltados para defesa do meio ambiente, elaboraram para mitigar os problemas dos recursos hídricos enfrentados pelos estados brasileiros. No entanto, pouco se tem feito efetivamente para diminuir a contaminação desses corpos hídricos ou otimizar o seu aproveitamento.

A prática do aproveitamento da água proveniente de ar condicionado, no país, encontra-se em expansão. Estudos têm mostrado que é viável o uso da água condensada dos aparelhos de ar condicionado para diversos fins, dentre eles: lavagem de pisos, descargas sanitárias, jardinagem e até cultivos de plantas para chás. Contudo, ainda são necessários mais estudos para difundir esta prática de aproveitamento para outros fins e contribuir para redução do desperdício desse bem escasso (CARVALHO et. al, 2016).

\section{Metodologia}

O experimento foi realizado no IFMA-Campus Codó, localizado a $5 \mathrm{~km}$ da sede do Município de Codó-Ma, Povoado Poraquê, Zona Rural, com as coordenadas geográficas de $4^{\circ}$ 26' 51' 'S, 43 52' 57' O e com altitude de $48 \mathrm{~m}$ acima do nível do mar. Esse trabalho foi do tipo de pesquisa quantitativa, o local de desenvolvimento da coleta tem uma estrutura física grande, as análises foram feitas exclusivamente nos seguintes pavilhões do Campus que se apresentam em 3 blocos com total de 60 ar-condicionado por bloco: Bloco A (Ensino Médio $1^{\circ}$ ano) 20 ar-condicionado, Bloco B (Ensino Médio $2^{\circ}$ e $3^{\circ}$ ano) 20 ar-condicionado e Bloco C (Ensino Superior) 20 ar-condicionado, com período integral das atividades acadêmicas, com isso determinou-se uma média mínima de 12 horas diárias. O primeiro passo foi realizar um levantamento dos seguintes parâmetros: número de aparelhos de ar condicionado em funcionamento, potência dos aparelhos - BTUs (British Thermal Units - Unidade Térmica 
Britânica); tempo de funcionamento dos aparelhos e temperatura no aparelho habitualmente utilizado em cada Bloco de sala de aula.

Para coleta dos dados foram utilizados um balde, uma proveta para medição e um cronômetro. A mensuração das vazões foi determinada pelo método direto, considerando a relação do volume pelo tempo. Como bem mostra todo este processo nas figuras abaixo.
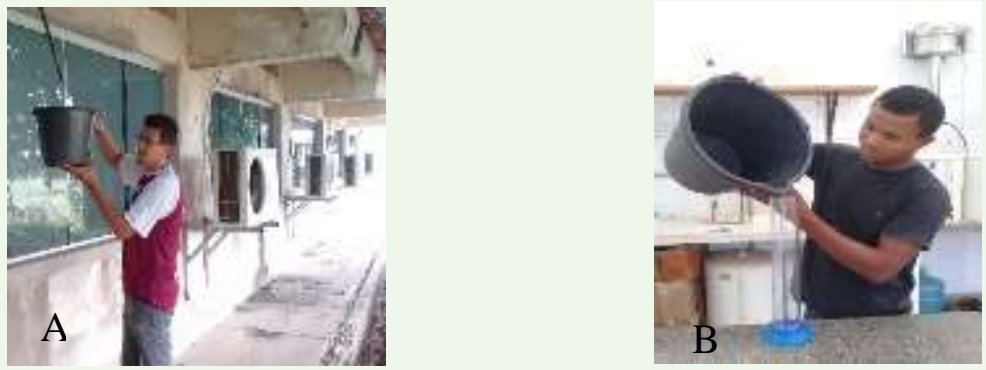

Figura 1: imagem A mostra a coletas da água proveniente dos ar condicionados, imagem B mostra a coletas medição e que serão utilizados para a mensuração das vazões dos aparelhos de ar condicionados. Fonte: Arquivo pessoal.

\section{Resultados e Discussões}

Em regiões tropicais, o uso dos aparelhos de ar condicionado para conforto térmico promove a geração de água resultante da condensação, que na maioria das vezes é desperdiçada, muitas vezes no solo ou então drenada para galerias pluviais (MOTA 2012).

Após coleta e análise dos dados, percebeu-se nas 3 coletas, médias diferentes em (ml), a $1^{\circ}$ média coletada no aparelho de ar-condicionado de 22000 BTUs da marca ADMIRAL foi de 405,5ml em $10 \mathrm{~min}$, nesse caso em 1 hora teríamos $2433 \mathrm{ml}$, já a $2^{\circ}$ média coletada no aparelho de ar-condicionado de 24000 BTUs da marca KING foi de $647 \mathrm{ml} \mathrm{em} 10 \mathrm{~min}$, nesse caso em 1 hora teríamos $3882 \mathrm{ml} \mathrm{a} 3^{\circ}$ e última média coletada no aparelho de ar-condicionado de 24000 da marca MIDIA foi de 588,8ml em 10 min, nesse caso em 1 hora teríamos 3532,8 ml. Para uma melhor compreensão, após a coleta foi obtida uma média geral de 547,1 ml a cada 10 min. Após a obtenção das médias foram realizados os cálculos para a obtenção dos dados desejados, como mostra os dados abaixo.

Quadro 1: Quantidade, Temperatura e volume médio coletado de aparelhos

\begin{tabular}{|c|c|c|c|c|c|c|c|}
\hline Marcas & Blocos & $\begin{array}{c}\text { Temperatura } \\
\mathrm{C}^{\circ}\end{array}$ & $\begin{array}{c}\text { Quantidade } \\
\text { por bloco }\end{array}$ & $\begin{array}{c}\text { Potência } \\
\text { BTUs }\end{array}$ & $\begin{array}{c}\text { Total de } \\
\text { BTUs }\end{array}$ & $\begin{array}{c}\text { Tempo } \\
\text { de coleta } \\
(\mathrm{min})\end{array}$ & $\begin{array}{c}\text { Volume } \\
\text { coletado } \\
(\mathrm{ml})\end{array}$ \\
\hline ADMIRAL & $\mathrm{B}$ & $16^{\circ}$ & 20 & 22000 & 440000 & 10 & 405,5 \\
\hline MIDEA & $\mathrm{A}$ & $16^{\circ}$ & 20 & 24000 & 480000 & 10 & 588,8 \\
\hline KING & $\mathrm{C}$ & $16^{\circ}$ & 20 & 24000 & 480000 & 10 & 647 \\
\hline \multicolumn{2}{|c|}{ Médi } & $16^{\circ}$ & 20 & 23333,33 & 1400000 & 10 & 547,1 \\
\hline
\end{tabular}




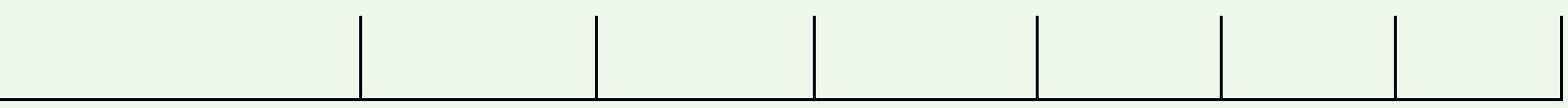

Quadro 2: Vazão média estimada a longo prazo de acordo com os horários de funcionamento do IFMA CAMPUS CODÓ.

\begin{tabular}{|c|c|c|c|}
\hline & $\begin{array}{c}\text { Horário de } \\
\text { funcionamento }(\mathrm{h})\end{array}$ & $\begin{array}{c}\text { Vazão gerada } \\
(\mathrm{L} / \mathrm{h})\end{array}$ & $\begin{array}{c}\text { Vazão gerada } \\
\left(\mathrm{M}^{3} / \mathrm{h}\right)\end{array}$ \\
\hline Dia (seg-sex) & 13 & $2.560,9$ & 2,5609 \\
\hline Semana & 70 & $13.787,2$ & 13,7872 \\
\hline Mês & 280 & $55.148,8$ & 55,1488 \\
\hline Ano & 2520 & $496.339,2$ & 496,3392 \\
\hline
\end{tabular}

Um dos problemas associados à problemática da água de reúso urbano não potável são o custo e a dificuldade operacional (MORELLI, 2005).

Como mostra os dados obtidos, a quantidade de água condensada é relativamente alta. Desta forma, a alternativa da implantação do sistema de reuso dessa água resolverá problemas como o desperdício excessivo da água. Assim, como a eliminação danosa a estrutura do prédio e de possíveis focos de mosquito da dengue ocasionadas pelo acúmulo de líquido condensado no chão (CABRAL, 2015).

\section{Conclusões}

A partir da análise quantitativa simples, podemos observar que é viável o reaproveitamento da água proveniente de aparelhos de ar condicionado para usos não domésticos, como: serviço de limpeza geral da instituição, jardinagem, descarga sanitária, irrigação de pequenos projetos, etc. A simples análise pode nos mostrar que os pontos coletados geram em média $55 \mathrm{~m}^{3}$ de água desperdiçada por mês. $\mathrm{Na}$ instituição são utilizados poços artesianos, havendo assim, um menor gasto em relação as demais instituições de ensino que fazer o pagamento de consumo de água. Essa simples coleta foi realizada em período chuvoso, porém, em meses mais quentes a vazão estimada seria bem maior.

Para um maior aproveitamento dessa água condensada a instituição poderia investir em pequenos projetos de pesquisa, atribuindo assim, um destino adequado para essa água que seria desperdiçada.

\section{Referências}

MOTA, J.R.; et al. UTILIZAÇÃO DA ÁGUA DE SISTEMAS DE AR CONDICIONADO VISANDO O DESENVOLVIMENTO SUSTENTÁVEL, Paraná agosto de 2012. 
JACOBI, P. EDUCAÇÃO AMBIENTAL, CIDADANIA E SUSTENTABILIDADE. Cadernos de Pesquisa, n. 118, p. 189-205, 2003.

CARVALHO, I.M.; et al. ANÁLISE QUANTITATIVA E QUALITATIVA DE ÁGUA PROVENIENTE DE APARELHO DE AR CONDICIONADO VISANDO O SEU

REAPROVEITAMENTO, Sergipe novembro de 2016.

REBOUCAS, R. F.; et al. REUTILIZAÇÃO

DA ÁGUA DOS APARELHOS DE AR CONDICIONADO DE UMA ESCOLA DE ENSINO FUNDAMENTAL NO MUNICÍPIO DE ICAPUÍ-CE, Natal- RN outubro de 2016.

MORELLI, E. B. REUSO DE ÁGUA NA LAVAGEM DE VEÍCULOS. Dissertação (Mestrado em Engenharia)- Escola Politécnica da Universidade de São Paulo, São Paulo, 2005. Disponível em. Acesso em 11 de agosto de 2018.

CABRAL, F. S.: et al. SUSTENTABILIDADE APLICADA A PARTIR DO

REAPROVEITAMENTO DE ÁGUA DE CONDICIONADORES DE AR, XXXV ENCONTRO

NACIONAL DE ENGENHARIA DE PRODUÇÃO Perspectivas Globais para a Engenharia de Produção, Fortaleza-CE outubro de 2015. 